\title{
Change of education strategy associated with slippage in Canadian hypertension awareness treatment and control rates
}

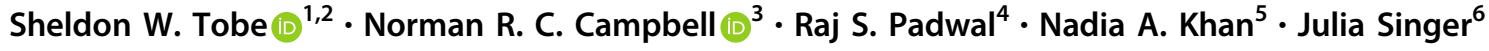

Received: 21 September 2020 / Revised: 20 February 2021 / Accepted: 23 February 2021 / Published online: 25 March 2021

(c) The Author(s), under exclusive licence to Springer Nature Limited 2021

Continuing professional development (CPD) is essential for maintaining clinical competence for health care providers. Keeping up to date with the latest evidence also helps to maintain confidence in our clinical knowledge and our patients' and colleagues' confidence in us as well. New evidence from clinical observation, chart reviews, prospective cohort studies, randomized trials, and meta-analyses helps us improve our knowledge and skills. Clinical practice guidelines derived from the best of this evidence are critically appraised and reviewed by national content experts, and using some form of consensus process, revised, and updated over time. Guidelines provide signposts for clinical practice, helping clinicians remain at the cutting edge of best practices. Putting this new knowledge into practice is facilitated by the principles of Education Theory. This process can be contrasted with the "infodemic" on COVID-19, including its adverse impact on hypertension management [1]. For the management of the pandemic, the lack of explanatory and even pragmatic controlled clinical trials, and reliance on observational data, has led to heterogeneity of policies and practice, with attendant erosion of confidence in the medical system in many jurisdictions.

Hypertension guidelines are an excellent example of how an organized process can positively impact practices even though the subject matter is expansive, heterogenous, and often seemingly conflicting. National hypertension guidelines are more similar than dissimilar despite often genuine

Sheldon W. Tobe

sheldon.tobe@sunnybrook.ca

University of Toronto, Toronto, ON, Canada

2 Northern Ontario School of Medicine, Sudbury, ON, Canada

3 University of Calgary, Calgary, AB, Canada

4 University of Alberta, Edmonton, AB, Canada

5 University of British Columbia, Vancouver, BC, Canada

6 McMaster University, Hamilton, ON, Canada disagreements about the same data, and while differences exist, the most important distinction is that substantial changes in these guidelines can occur over time. As an example, in 2017 evidence from the SPRINT study [2] pushed the American Heart Association (AHA) to a tipping point for lower blood pressure targets, and the need for a well-coordinated national approach to CPD. The new guideline changed blood pressure diagnostic and treatment thresholds and targets, and was accompanied by a massive educational process, including published manuscripts, online resources, toolkits for clinicians, patients, and allied health care applications, all coordinated through the AHA website [3]. A national surveillance effort to assess the uptake of the new guidelines and their impact will be conducted as new data are released on a biennial cycle [4]. The importance of maintaining consistent implementation and dissemination strategies is shown by recent surveillance data from Canada-once a world leader in hypertension awareness treatment and control-demonstrating how control rates can fall when these efforts miss their mark.

In the 2000s, CHEP, the Canadian Hypertension Education Program was a uniquely Canadian knowledge translation (KT) program focused on improving the awareness, treatment, and control of hypertension through the dissemination and implementation of evidence-based guidelines and recommendations [5]. Its Implementation and Dissemination Task Force was composed of multidisciplinary and interprofessional health care volunteers: all hypertension experts, organized into committees and task forces whose energy and commitment sustained and ensured program success [6]. Hypertension treatment in Canada improved significantly between 1990 and 2000, attributable to the combination of a strong, publicly funded primary health care system and a national strategic plan supporting the development and widespread implementation of clinical practice guidelines, as well as national and regional monitoring, with engagement and financial support from the national public health agency [7, 8]. By the mid2000s, Canada emerged as a world leader in hypertension 
care, with nationally reported rates of hypertension treatment at $80 \%$ and control in both men and women at $68 \%$, outperforming other countries over the same time period [9]. In partnership with the Public Health Agency of Canada and Statistics-Canada providing access to national databases, an association between Canada's hypertension KT program and improved cardiovascular outcomes was found [10].

These results supported the clinical practice guidelinebased undertaking of knowledge generation, knowledge dissemination and implementation, and evaluation of process effectiveness. Following these publications, Canadian hypertension experts were invited to partner with hypertension experts in other countries [11]. These included Brazil, Saudi Arabia, Vietnam [12], Mongolia, and Russia, and recently China [13] to improve the awareness, treatment, and control of hypertension with interventions based on CPD principles and patient engagement strategies. As an example, in the Yaroslavl region of Russia, the program included a strong emphasis on CPD and over 4 years was associated with a 95\% relative increase in control of hypertension, and an almost $25 \%$ reduction in stroke incidence [14]. A key factor in the success of each of these countries was governmental support for the hypertension program and committed hypertension experts linked to national and local hypertension societies, all of whom actively focused on implementation efforts.

Dissemination and implementation of the Canadian hypertension guideline was the responsibility of the Implementation Task Force, composed of many multidisciplinary and interprofessional subgroups each focused on only one or two tools or educational resources. Each subgroup had strong clinical community roots, could perform focus groups, had linkages to national professional organizations (family medicine, nursing, dietitians, pharmacists, etc.), and included at least one guideline developer to ensure accuracy in interpreting the practice guideline. The linkage back to the hypertension guideline was critical to ensure accuracy when translating a difficult to implement recommendations into feasible actions for primary care. Task Force leads and subgroup members were volunteers who could request assistance from Hypertension Canada's staff. Subgroup leads were chosen for their expertise, passion, and academic interest in the topic of focus, and it was expected that volunteers would publish reports stemming from their work. A small amount of financial or staff time resource was all that was usually required by each subgroup to complete tasks. Each of the educational tools was developed with the specific KT goal of changing behaviors to improve health outcomes [15]. These tools were developed based on adult learning principles, also recognizing different learning styles and directed at doctors and other health care professionals $[16,17]$. CPD was used to bridge the gap between up-to-date evidence-based recommendations and application into clinical practice.

The change in government support led to a focus on other sources of revenues to cover expenses, and coupled with a change in strategic direction in 2011 where staff became responsible for determining the project priorities asking the volunteers to assist, resulted in fewer, but more resource-intensive products. This change led to sharp reductions in volunteer driven implementation and dissemination efforts, in favor of paid staff leading these efforts. The committees of grass-roots members and linkages to national organizations were largely lost and many volunteers became inactive. Support for national CPD and ongoing monitoring from the federal government dwindled, possibly due to the assumption that the excellent control rates would simply continue. Similarly, support from the pharmaceutical industry was reduced as patents for antihypertensive agents expired. Additional factors impacting on implementation and dissemination efforts included declining government support for hypertension surveillance, industry partnership terminations, and the restructuring of several hypertension organizations into one larger organization, with much less emphasis on guideline implementation and evaluation.

In a recent Canadian surveillance study on hypertension rates, Leung et al. [18] found blood pressure treatment and control rates remained stable from 2007 to 2017 in men, at $78.9 \%$ and $65.4 \%$ respectively, however, over the same time period treatment and control rates for women, fell from 82.2 and $67.0 \%$ to 65.2 and $49.2 \%$. Such a sex disparity is alarming, since death and disability rates will increase as BP control falls. The reasons underlying these sex differences are unclear and do not appear to be associated with any significant demographic shifts or differences in the frequency of hypertension or related comorbidities in the general population.

In summary, hypertension awareness, treatment, and control in Canada improved following dissemination and implementation CPD programs produced by volunteer hypertension experts linked to national guideline development, working through multidisciplinary and interprofessional teams, and partly supported by national public health organizations. Improved hypertension control rates were associated with improved national outcomes, coupled with a more educated and integrated health care community. We have now documented that straying from the principles of CPD can erode and reverse previous achievements. Our challenge is now to assess, adapt, and then regain our previous accomplishments.

\section{Compliance with ethical standards}

Conflict of interest NRCC has no COI to declare. RSP is CEO of $\mathrm{mmHg}$ Inc., a digital health company improving hypertension 
measurement, monitoring, and control. NRCC, NAK, and JS have no COI to disclose. SWT is country PI for an international study on diabetic nephropathy with Bayer. He has received honorarium from the LIV agency and CHEP+ a not-for-profit CPD organization that provides Canadian accredited continuing education.

Publisher's note Springer Nature remains neutral with regard to jurisdictional claims in published maps and institutional affiliations.

\section{References}

1. Nadar SK, Tayebjee MH, Stowasser M, Byrd JB. In: Managing hypertension during the COVID-19 pandemic. J Hum Hypertens. 2020;34:415-417. https://doi.org/10.1038/s41371-020-0356-y

2. Group SR. A randomized trial of intensive versus standard bloodpressure control. N Engl J Med. 2015;2015:2103-16.

3. Flack JM, Calhoun D, Schiffrin EL. The new ACC/AHA hypertension guidelines for the prevention, detection, evaluation, and management of high blood pressure in adults. Am J Hypertens. 2018;31:133-5.

4. Ahluwalia N, Dwyer J, Terry A, Moshfegh A, Johnson C. Update on NHANES dietary data: focus on collection, release, analytical considerations, and uses to inform public policy. Adv Nutr. 2016;7:121-34.

5. Tobe SW, Touyz RM, Campbell N. The Canadian Hypertension Education Program - a unique Canadian knowledge translation program. Can J Cardiol. 2007;23:551-5.

6. Hua D, Carter S, Bellerive J, Allu SO, Reid D, Tremblay G, et al. Bridging the gap: innovative knowledge translation and the canadian hypertension education program. Can J Cardiol. 2012;28:258-61.

7. Tobe SW. Management of hypertension: regional variations in a greatly improved landscape. Can J Cardiol. 2010;26:415-6.

8. Campbell NR, Brant R, Johansen H, Walker RL, Wielgosz A, Onysko $\mathrm{J}$, et al. Increases in antihypertensive prescriptions and reductions in cardiovascular events in Canada. Hypertension. 2009;53:128-34
9. Schiffrin EL, Campbell NR, Feldman RD, Kaczorowski J, Lewanczuk R, Padwal R, et al. Hypertension in Canada: past, present, and future. Ann Glob Health. 2016;82:288-99.

10. Onysko J, Maxwell C, Eliasziw M, Zhang JX, Johansen H, Campbell NR. Large increases in hypertension diagnosis and treatment in Canada after a healthcare professional education program. Hypertension. 2006;48:853-60.

11. Campbell NR, Sheldon T. The Canadian effort to prevent and control hypertension: can other countries adopt Canadian strategies? Curr Opin Cardiol. 2010;25:366-72.

12. Khuong QL, Bui PL, Adler AJ, Shellaby JT, Aerts A, McGuire H, et al. Effect of community-based intervention on self-management of blood pressure among hypertensive adults: findings from the Communities for Healthy Hearts Quasi-experimental Study in Vietnam. J Glob Health Sci. 2020;2:1-14.

13. Fan W, Xie F, Wan Y, Campbell NR, Su H. The impact of changes in population blood pressure on hypertension prevalence and control in China. J Clin Hypertens. 2020;22:150-56.

14. Mozheyko M, Eregin S, Danilenko N, Vigdorchik A, Tobe SW, Campbell N, et al. Hypertension in Russia: changes observed after 4 years of a comprehensive health system improvement program in the Yaroslavl Region. J Clin Hypertens. 2017;19:198-204.

15. Davis D, Evans M, Jadad A, Perrier L, Rath D, Ryan D, et al. The case for knowledge translation: shortening the journey from evidence to effect. BMJ. 2003;327:33-5.

16. Knowles MS, Holton III EF, Swanson RA. In: The adult learner: the definitive classic in adult education and human resource development. New York; 8th edn; Routledge; 2014.

17. Kolb DA, Boyatzis RE, Mainemelis C. Experiential learning theory: previous research and new directions in perspectives on thinking, learning, and cognitive styles. In: R. J. Sternberg \& L.-f. Zhang editors, Educational Psychology Series. Lawrence Erlbaum Associates Inc., Mahwah, New Jersey; 2001.

18. Leung AA, Williams JVA, McAlister FA, Campbell NRC, Padwal RS, Hypertension Canada's R, et al. Worsening hypertension awareness, treatment, and control rates in Canadian women between 2007 and 2017. Can J Cardiol. 2020;36:732-9. 